\title{
Correlations of Three Polymorphisms in Beta2-Adrenergic Receptor Gene with Chronic Obstructive Pulmonary Disease Risk and Related Phenotypes: A Meta-Analysis
}

\author{
Type \\ Research paper
}

\section{Keywords}

polymorphism, gene, meta-analysis, chronic obstructive pulmonary disease, $\beta 2$-adrenergic receptor

\begin{abstract}
Introduction

The gene encoding $\beta 2$-adrenergic receptor (ADRB2) is a candidate gene for chronic obstructive pulmonary disease (COPD), yet the results are not often reproducible. We aimed to assess the association of ADRB2 genetic polymorphisms (rs1042713, rs1042714, and rs1800888) with COPD risk and COPD-related phenotypes via a meta-analysis.
\end{abstract}

\section{Material and methods}

Literature search, quality evaluation, and data extraction were completed independently and in duplicate. Effect-size estimation is expressed as odds ratio (OR) or weighted mean difference (WMD) with $95 \%$ confidence interval $(\mathrm{Cl})$.

\section{Results}

Total 15 articles were meta-analyzed, including 12 articles (2917/8807 patients/controls) for COPD risk, and 6 articles (18350 subjects) for COPD-related phenotypes. Overall, there was no detectable significance for the association of rs 1042713 (OR, 95\% Cl: 1.02, 0.88-1.19) and rs 1042714 (1.01, $0.85-1.20)$ with COPD risk, and only marginal significance retained for rs 1800888 (1.31, 1.00-1.72). In subsidiary analyses, the association of rs 1042713 and rs 1042714 with COPD risk was significant in populations of Asian origin (OR: 1.66 and 1.351, 95\% Cl: 1.13-2.44 and 1.02-1.79). Additionally, carriers of rs 1042713 AA genotype had significantly lower levels of FEV1 (WMD, $95 \% \mathrm{Cl}:-0.011 \mathrm{~L}$, -0.026 to -0.004 ) than carriers of GG genotypes, and FVC\% predicted levels were significantly increased for the comparisons of rs1042713 AA genotype (6.914, 4.829 to 8.999) and AG genotype $(4.249,2.925$ to 5.573$)$ with $G G$ genotype. There were low probabilities of publication bias.

\section{Conclusions}

Our findings suggest that contribution of ADRB2 genetic polymorphisms to COPD risk is small and ethnicity-dependent, and to COPD-related phenotypes is significant. 


\section{Correlations of Three Polymorphisms in Beta2-Adrenergic Receptor Gene with}

Chronic Obstructive Pulmonary Disease Risk and Related Phenotypes: A Meta-Analysis

Guan Wang ${ }^{\mathrm{a}, \mathrm{b}, *}$, Danni He $\mathrm{He}^{\mathrm{c}, *}$, Yang Wang ${ }^{\mathrm{d}, *}$, Haifeng Jin ${ }^{\mathrm{a}}$, Lijie Yao ${ }^{\mathrm{a}}$, Yang Jiang ${ }^{\mathrm{a}}$, Deshan Zhou $^{\mathrm{b}}$, Lei Shen ${ }^{\mathrm{a}, \#}$, and Wenquan Niu ${ }^{\mathrm{c}, \mathrm{e}, \#}$

\section{Author Affiliations:}

a. Department of Anatomy, Qiqihar Medical University, Qiqihar, Heilongjiang, China.

b. Department of Histology and Embryology, School of Basic Medical Sciences, Capital Medical University, Beijing, China.

c. Institute of Clinical Medical Sciences, China-Japan Friendship Hospital, Beijing, China.

d. Department of Medical Service Supervision, Qiqihar Health Inspection Bureau, Qiqihar, Heilongjiang, China.

e. National Clinical Research Center for Respiratory Diseases, Beijing, China.

*These authors contributed equally to this work.

${ }^{\#}$ Correspondence should be addressed to:

Wenquan Niu, Ph.D. or Lei Shen, Ph.D.

Address: No. 2 Yinghua East Street, Chaoyang District, Beijing 100029, China. Tel \& Fax: 86-01-8420 6414 or No.333 Bukui North Street, Jianhua District, Qiqihar 161006, China. Tel \& Fax: 86-452-2663809.

E-mail: niuwenquan_shen@163.com (W.N.) or shenlei815@yahoo.com (L.S.). 


\begin{abstract}
The gene encoding $\beta 2$-adrenergic receptor $(A D R B 2)$ is a candidate gene for chronic obstructive pulmonary disease (COPD), yet the results are not often reproducible. We aimed to assess the association of $A D R B 2$ genetic polymorphisms (rs1042713, rs1042714, and rs1800888) with COPD risk and COPD-related phenotypes via a meta-analysis.

Literature search, quality evaluation, and data extraction were completed independently and in duplicate. Effect-size estimation is expressed as odds ratio (OR) or weighted mean difference (WMD) with $95 \%$ confidence interval (CI).

Total 15 articles were meta-analyzed, including 12 articles (2917/8807 patients/controls) for COPD risk, and 6 articles (18350 subjects) for COPD-related phenotypes. Overall, there was no detectable significance for the association of rs1042713 (OR, 95\% CI: 1.02, 0.88-1.19) and rs1042714 (1.01, 0.85-1.20) with COPD risk, and only marginal significance retained for rs 1800888 (1.31, 1.00-1.72). In subsidiary analyses, the association of rs1042713 and rs1042714 with COPD risk was significant in populations of Asian origin (OR: 1.66 and 1.351, 95\% CI: 1.13-2.44 and 1.02-1.79). Additionally, carriers of rs1042713 AA genotype had significantly lower levels of FEV1 (WMD, 95\% CI: -0.011 L, -0.026 to -0.004$)$ than carriers of GG genotypes, and FVC\% predicted levels were significantly increased for the comparisons of rs1042713 AA genotype (6.914, 4.829 to 8.999) and AG genotype $(4.249,2.925$ to 5.573) with GG genotype. There were low probabilities of publication bias.
\end{abstract}

Our findings suggest that contribution of $A D R B 2$ genetic polymorphisms to COPD risk is small and ethnicity-dependent, and to COPD-related phenotypes is significant.

Key Words: Chronic obstructive pulmonary disease; $\beta 2$-adrenergic receptor; Gene; Polymorphism; Meta-analysis. 


\section{INTRODUCTION}

It is widely believed that the development of chronic obstructive pulmonary disease (COPD) is largely under genetic control. ${ }^{1}$ COPD is a complex disease of high prevalence, and it has become the third leading cause of morbidity and mortality worldwide. ${ }^{2}$ As reported by the Global Burden of Disease (GBD) study, an estimated 174.5 million adults have prevalent COPD in 2015. ${ }^{3}$ Our recent national survey indicated that in China, the estimated total number of COPD patients aged 20 years or older was 99.9 million in $2015 .{ }^{4}$ Currently, debates concerning how to early identify subjects at risk for COPD are still ongoing and unsettled. ${ }^{5}$ Identification of genetic markers hence, has proven to be feasible and effective, as heritability of COPD affection status was estimated to be $37.7 \% .^{6}$

A considerable number of genes and polymorphisms have been assessed as candidate determinants of the risk for COPD in current literature. ${ }^{7,8}$ Many case-control studies have addressed in particular the putative contribution of $\beta 2$-adrenergic receptor (ADRB2) gene to COPD susceptibility. ADRB2 is a member of the $\mathrm{G}$ protein-coupled receptor superfamily. Several polymorphisms in ADRB2 gene have been widely evaluated in association with COPD risk, including rs1800888 (Thr164Ile), rs1042713 (Arg16Gly) and rs1042714 (Gln27Glu). For instance, Ho and colleagues ${ }^{9}$ for the first time focused on ADRB2 gene and found that Gly16 allele increased the susceptibility to the development of COPD, and Gln27 was associated with the severity of COPD in a Chinese population. Another study in Germans by Vacca and colleagues ${ }^{10}$ showed that Gly16 allele predisposed to COPD development, yet no relevance was noted for Gln27Glu polymorphism. A thorny issue facing human geneticists is the inconsistent findings across different studies, possibly due to diverse genetic backgrounds, heterogeneous subject characteristics or insufficient study power of individual studies. ${ }^{11}$ To shed some light on this issue, we employed the meta-analytical method and tested the hypothesis that $A D R B 2$ genetic polymorphisms are potential candidates in predisposition to the development of COPD.

To be specific, we reviewed medical literature to identify eligible articles that assessed the association of genetic polymorphisms in ADRB2 gene with the risk of having COPD, pooled the results and explored possible causes of between-study heterogeneity. Meanwhile, we also interrogated the association of three polymorphisms (rs1042713, rs1042714, and rs1800888) with COPD-related phenotypes.

\section{METHODS}

The meta-analysis was conducted according to the guidelines of the Preferred 
1 Reporting Items for Systematic Reviews and Meta-Analyses (PRISMA) statement. ${ }^{12}$ The

PRISMA checklist and flow diagram are presented in Supplementary Table 1 and Figure 1, respectively.

\section{Search Strategy}

We searched all potentially eligible studies from PubMed, EMBASE, Web of Science, and Google Scholar published before August 29, 2020. We used the title or abstract search strategy with following entries: ('ADRB2' OR ‘ $\beta 2$-adrenergic receptor' OR ‘ $\beta 2$ adrenergic receptor' OR 'beta2-adrenergic receptor' OR 'beta2 adrenergic receptor' OR 'beta-2-adrenergic receptor' OR 'ADRBR' OR 'B2AR' OR 'BETA2AR' OR 'ADRB2R' OR ' $\beta$-2-adrenergic receptor' OR 'adrenoceptor') AND ('polymorphism' OR ‘variant' OR ‘variation' OR ‘mutation' OR ‘allele' OR ‘genotype' OR ‘SNP') AND ('chronic obstructive pulmonary' OR ‘COPD' OR 'obstructive pulmonary'). We also checked reference lists of identified publications for other potentially relevant studies. Literature search was completed by two authors (Guan Wang and Yang Wang). All citations were combined, and duplicates were manually excluded.

\section{Selection Criteria}

Articles were inclusive if a) the genotype or allele counts of $A D R B 2$ genetic polymorphisms were provided in both COPD patients and controls; $b$ ) the mean and standard deviation or standard error or quartile or $95 \%$ confidence interval (CI) of COPD-related phenotypes (including FEV1\%Pred or FEV1 or FVC or FVC\% or FEV1/FVC) and genotype counts were available; c) COPD was diagnosed by generally accepted standards; d) polymorphisms were genotyped using validated methods. Only articles published in the English language and conducted in populations were included, and articles published in form of conference abstract, letter to the editor or correspondence, case reports or case series, or reviews or meta-analyses were excluded.

Per the selection criteria formulated above, two authors (Guan Wang and Yang Wang) independently assessed the eligibility of each potential article for inclusion, and the results were compared and disagreement was resolved by consensus.

\section{Data Extraction}

The following data were extracted from each eligible study into an unified designed table: the first author's surname, year of publication, country, ethnicity of the study subjects, study design, sample size, diagnosis of COPD, source of cases and controls, age, gender, match, body mass index, smoking status, pack years of smoking, forced expiratory volume in one second (FEV1), forced expiratory volume in one second \% predicted (FEV1/Pred\%), 
1 forced vital capacity (FVC), forced vital capacity \% predicted (FVC/Pred\%), the ratio of

2 forced expiratory volume to forced vital capacity in one second (FEV1/FVC), the number of

3 subjects with different genotypes of ADRB2 genetic polymorphisms in both COPD patients and controls. Data abstracted by the two authors (Guan Wang and Yang Wang) were checked for coherence, and any divergence was resolved by resorting to original context until a consensus was reached.

\section{Quality score assessment}

The quality of each study was independently assessed by two authors (Guan and Yang) according to the score system by Thakkinstian ${ }^{13,14}$ displayed in Supplementary Table 2. The quality scores were based on both traditional epidemiologic considerations and genetic issues. ${ }^{14}$ The total scores ranged from 0 to 15 .

\section{Statistical Analyses}

Statistical analyses were conducted by the STATA software Release 14.1 (Stata Corp, College Station, TX). Considering the limited number of minor homozygous genotypes, COPD risk prediction is evaluated under the allele and dominant models of inheritance only. The association between three polymorphisms in ADRB2 gene and COPD risk was evaluated by weighted odds ratio (OR) with $95 \% \mathrm{CI}$ in COPD patients relative to controls. The secondary outcome of this meta-analysis was the difference in COPD-related phenotypes across genotypes, as expressed as weighted mean difference (WMD) with 95\% CI. Summary OR and WMD were calculated under the random-effects model, due to assumption of clinical and methodological heterogeneity across studies, which can often cause statistical heterogeneity. Additionally, in case of no statistical heterogeneity, both fixed-effects model and random-effects model yield very similar results, and when statistical heterogeneity is present, random-effects model is preferred. ${ }^{15}$

Statistical heterogeneity was quantified using the inconsistency index $\left(I^{2}\right)$ statistic (ranging from $0.0 \%$ to $100.0 \%$ ), which is defined as the percentage of observed between-study variability that is due to heterogeneity rather than chance. If $I^{2}$ exceeds $50 \%$ or $\chi^{2}$-based probability is less than $10 \%$, it indicates significant heterogeneity.

Cumulative and sensitivity analyses were performed to identify the influence of individual studies on overall estimation.

Funnel plots were used to assess the probability of publication bias and small-study effect. If funnel shape was asymmetric, it might suggest an association between pooled estimate and study size (publication bias or small study bias). The Egger's test was used to objectively assess funnel asymmetry, and the trim-and-fill method was used to calculate 
1 probable missing studies due to publication bias. On the side, to estimate the extent to which

2 one or more covariates explain heterogeneity, meta-regression was employed as an extension

3 to random-effects meta-analysis.

4

\section{RESULTS}

\section{Qualified Studies}

Initial literature search retrieved 53 articles published in the English language, and two additional articles were identified through the other sources. Based on predefined inclusion and exclusion criteria, 15 articles were eligible for analysis. ${ }^{9,10,16-28}$ There were 12 articles involving 15 studies (2917 patients and 8807 controls) that focused on the association of ADRB2 genetic polymorphisms (rs1042713 [Arg16Gly], rs1042714 [Gln27Glu], and rs1800888 [Thr164Ile]) with the risk for COPD, and 6 articles involving 10 studies (18350 subjects) that focused on the changes in either FEV1 or FEV1\%Pred or FVC or FVC\%Pred or FEV1/FVC across genotypes of ADRB2 genetic polymorphisms, if available. The score of involved studies was greater than or equal to 10 .

\section{Baseline Characteristics}

Baseline characteristics of eligible studies are presented in Table 1. All studies were published between 2001 and 2018. Total sample size ranged from 106 to 8470. Five studies were prospective in design, and 9 studies were retrospective. COPD was diagnosed according to the $\mathrm{GOLD}^{29}$ guideline in all, but two (according to $\mathrm{ATS}^{30}$ ) studies.

\section{Overall Association with COPD Risk}

Figure 2 shows the forest plots of three polymorphisms in ADRB2 gene associated with the risk for COPD under the allele model of inheritance. There are 13, 12, and 2 studies eligible for rs1042713, rs1042714, and rs1800888, respectively. Overall, there was no detectable significance for the association of rs 1042713 (OR: $1.02,95 \%$ CI: 0.88 to 1.19) and rs1042714 (OR: $1.01,95 \%$ CI: 0.85 to 1.20 ) with COPD risk, with moderate evidence of heterogeneity $\left(I^{2}: 60.2 \%\right.$ and $66.5 \%$, respectively). As for rs 1800888 , the mutant allele of this polymorphism was significantly associated with a $31 \%$ increased risk of COPD (OR: 1.31, 95\% CI: 1.00 to 1.72$)$, without heterogeneity $\left(I^{2}: 0.0 \%\right)$.

\section{Subsidiary Association with COPD Risk}

Table 2 shows the effect size estimates by subgrouping studies according to sample size, ethnicity, study design, matched status, COPD diagnosis, and sources of cases and controls respectively under both allele and dominant models. Because of the limited number of eligible studies for rs1800888, subsidiary analyses were only conducted for rs1042713 and 
1 rs1042714. Under the allele model, no hint of significance was observed for both

polymorphisms across all subgroups. By contrast, under the dominant model, the association of both polymorphisms with COPD risk was significant in populations of Asian origin (for rs1042713, OR: $1.66,95 \%$ CI: 1.13 to 2.44 ; for rs1042714, OR: $1.35,95 \%$ CI: 1.02 to 1.79 ), without heterogeneity $\left(I^{2}: 0.0 \%\right.$ and $1.7 \%$, respectively). In addition, rs 1042713 was associated with ATS-diagnosed COPD under the dominant model (OR: 2.17, 95\% CI: 1.14 to $\left.4.12, I^{2}: 0.0 \%\right)$.

\section{Cumulative and Influential Analyses}

The plots of cumulative and influential analyses on the association of three studied polymorphisms in ADRB2 gene with COPD risk are displayed in Supplementary Figure 1.

\section{Publication Bias}

Begg's and filled funnel plots of three polymorphisms in ADRB2 gene associated with COPD risk are displayed in Figure 3. The probability of publication bias was low, as reflected the seemingly symmetry of Begg's funnel plots and as confirmed by Egger's tests (all $p>0.1$ ). Filled funnel plots revealed that only one study was assumed to be missing to make the funnel plot symmetrical for the association between rs1042713 and COPD risk.

\section{Overall and Subsidiary Association with COPD-Related Phenotypes}

Table 3 shows the association of two polymorphisms (rs1042713 and rs1042714) in $A D R B 2$ gene with COPD-related phenotypes in both overall and subsidiary analyses.

In overall analyses, carriers of rs1042713 AA genotype had significantly lower levels of FEV1 (WMD: -0.011 L, 95\% CI: -0.026 to -0.004) than carriers of GG genotypes, with no evidence of heterogeneity (both $I^{2}: 0.0 \%$ ). Levels of FVC\% predicted were significantly increased for the comparisons of rs1042713 AA genotype (WMD: 6.914, 95\% CI: 4.829 to 8.999) and AG genotype (WMD: 4.249, 95\% CI: 2.925 to 5.573) with GG genotype. Significant increase in FEV1/FVC was also found for the comparison of rs 1042714 CC genotype with GG genotype (WMD: 3.098, 95\% CI: 0.102 to 6.095).

In subsidiary analyses, $\mathrm{FVC} \%$ predicted was significantly increased in carriers of rs1042713 AA genotype (WMD: 6.990, 95\% CI: 4.897 to 9.083) and AG genotype (WMD: 4.250, 95\% CI: 2.923 to 5.577) related to GG genotype in populations of Caucasian origin. Significant increase in FEV1/FVC was also observed for the comparison of rs1042714 CC genotype with GG genotype in Caucasians (WMD: 3.120, 95\% CI: 0.010 to 6.230). Meta-regression Analyses

To further account for between-study heterogeneity within a multivariable frame-work, we performed meta- regression analyses by incorporating various study-level 
1 covariates including averaged levels of FEV1\%Pred, FVC\%Pred, FEV1, FVC, and

2 FEV1/FVC ratio between $A D R B 2$ gene polymorphisms and controls. In Figure 4, we interestingly and exclusively observed that study design was a significant source of between-study heterogeneity by rs1042713 (FEV1\%Pred (P=0.009), FVC\%Pred (P=0.048)) and rs1042714 (FEV1 ( $\mathrm{P}=0.035)$, FEV1/FVC ratio $(\mathrm{P}=0.000))$.

Although overall analyses failed to detect any significance for rs1042713 and rs1042714, subsidiary analyses indicated that both polymorphisms were potential candidate loci in susceptibility to COPD in Asians. In further genotype-phenotype analyses, carriers of mutant allele of rs1042713 had significantly higher levels of FVC\% predicted than those with the wild genotype, and homozygous mutant genotype of rs1042714 was associated with significantly increased FEV1/FVC levels relative to the corresponding homozygous wild genotype, and the effects were more obvious in Caucasians.

\section{DISCUSSION}

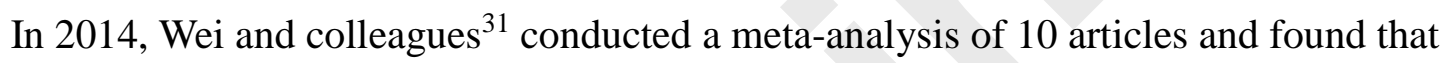
$A D R B 2$ gene rs 1042713 was a potential risk factor for the development of COPD in smoking Asian populations, but not in European descendents. In 2017, Nielsen and colleagues ${ }^{32}$ updated this meta-analysis by including 16 articles and additionally assessing the association of $A D R B 2$ gene three polymorphisms as the present study examined with therapeutic response to inhaled beta2-agonists in COPD, and they found null associations with COPD risk and treatment response. Extending the results of previous meta-analyses, we made more efforts to explore possible causes of between-study heterogeneity by subsidiary analyses, and additionally interrogated data on changes of COPD-related phenotypes across ADRB2 genotypes. On one hand, although our overall analyses consolidated previous results, subsidiary analyses revealed that the association between $A D R B 2$ gene and COPD risk may be depended on ethnicity and diagnosis of COPD. In view of ethnic differences, we agree that it is of importance to construct a database of genetic determinants related to COPD in each ethnic group, and deciphering the difference in the genetic profiles of different ethnic groups will help in unravelling the molecular mechanisms involved in COPD. Nevertheless, because of a small effect expected from studied polymorphisms in ADRB2 gene, studies of multiple genes and polymorphisms are needed to test a new hypothesis.

On the other hand, our genotype-phenotype analyses indicated that $A D R B 2$ genetic defects might lead to changes in FVC\% and FEV1/FVC. It is widely believed that COPD is a complex polygenic disease, which is the result of combinations of genetic and non-genetic 
1 factors, each of which contributes to a tiny fraction of disease risk. It might be speculated that the modulatory effect of a single locus in $A D R B 2$ gene on COPD-related phenotypes is not strong enough to result in a statistically significant risk for COPD. Also, we agree that success in characterizing genetic underpinning of COPD will depend on our capability to assess nonlinearities in the genotype-phenotype association, as well as possible gene-gene and locus-locus interactions known as epistasis.

Our findings are biologically plausible. There is experimental evidence suggesting that ADRB2 has a strong correlation with airway bronchodilation, and a predominant role in the treatment of obstructive pulmonary diseases via mediating the function of $\beta_{2}$-adrenergic agonists. ${ }^{33}$ The $\beta_{2}$-adrenergic agonists may inhibit the proliferation of human airway smooth muscle cells and neutrophil accumulation, and so the responsiveness of ADRB2 to $\beta_{2}$-adrenergic agonists thereby may play a vital role in regulating bronchial hyperresponsiveness and the development of COPD. ${ }^{31}$

Our results indicated that $A D R B 2$ gene rs1042713 and rs1042714 were potential candidate loci in susceptibility to COPD in Asians. It has been proved that ACE DD genotype $^{34}$ and $T N F$-alpha +489 G/A genotype ${ }^{35-38}$ were also risk factors specially in Asians. More bench works could be conducted to find whether synergistic effects of the three polymorphisms exist on COPD risk in Asians. Furthermore, more researches on genome-wide association study (GWAS) and epigenetics should be considered to help decipher the pathogenesis of COPD. ${ }^{35}$

There are several possible limitations for this present meta-analysis. Firstly, only studies published in English were retrieved, and selection bias is likely. It is estimated that grey literature may result in an overestimate of an association impact by an average of $12 \% .{ }^{39}$ Secondly, our analyses were based on cross-sectional observational data, which obviated comment on causality between ADRB2 gene and COPD risk, as well as COPD-related phenotypes. Thirdly, eligible studies on the association between rs1800888 and COPD are limited, and although this association was statistically significant, more studies are needed. Fourthly, a large panel of subsidiary analyses were conducted to appraise heterogeneity, as it is estimated that small sample size may lead to low statistical efficiency.

In conclusion, our findings suggest that the contribution of $A D R B 2$ genetic polymorphisms to COPD risk is small and ethnicity-dependent, yet the contribution to COPD-related phenotypes is significant but requires further confirmation. For practical reasons, further investigations in large, well-designed studies are required to elucidate the association between $A D R B 2$ genetic polymorphisms and COPD and its relevant phenotypes, 
as well as the molecular mechanisms of these polymorphisms in the pathogenesis of COPD.

\section{Acknowledgment}

This work was supported by the Science Research Foundation of Qiqihar Medical University

Conflict of Interest Statement: None declared.

Specific Author Contributions: W.N. and G.W. planned and designed the study; G.W. and

Y.W. searched literature, selected articles and abstracted data; D.H., L.S., H.J., L.Y., and S.Z.

did data preparation, quality control and data analyses; G.W. and W.N. wrote the manuscript.

1. Kurche JS, Schwartz DA. Deciphering the Genetics of Chronic Obstructive Pulmonary Disease. Am J Respir Crit Care Med. 2019;199(1):4-5.

2. Starkey MR, Plank MW, Casolari P, et al. IL-22 and its receptors are increased in human and experimental COPD and contribute to pathogenesis. Eur Respir J. 2019;54(1).

3. Collaborators GBDCRD. Global, regional, and national deaths, prevalence, disability-adjusted life years, and years lived with disability for chronic obstructive pulmonary disease and asthma, 1990-2015: a systematic analysis for the Global Burden of Disease Study 2015. The Lancet Respiratory medicine. 2017;5(9):691-706.

4. Wang C, Xu J, Yang L, et al. Prevalence and risk factors of chronic obstructive pulmonary disease in China (the China Pulmonary Health $[\mathrm{CPH}]$ study): a national cross-sectional study. Lancet. 2018;391(10131):1706-1717.

5. Baraldo S. Advances in chronic obstructive pulmonary disease genetics: building the picture one piece at a time. Lancet Respir Med. 2019;7(5):371-372.

6. Zhou JJ, Cho MH, Castaldi PJ, Hersh CP, Silverman EK, Laird NM. Heritability of chronic obstructive pulmonary disease and related phenotypes in smokers. Am J Respir Crit Care Med. 2013;188(8):941-947.

7. Hardin M, Silverman EK. Chronic Obstructive Pulmonary Disease Genetics: A Review of the Past and a Look Into the Future. Chronic Obstr Pulm Dis. 2014;1(1):33-46.

8. Korytina GF, Akhmadishina LZ, Aznabaeva YG, et al. Associations of the NRF2/KEAP1 pathway and antioxidant defense gene polymorphisms with chronic obstructive pulmonary disease. Gene. 2019;692:102-112.

9. Ho LI, Harn HJ, Chen CJ, Tsai NM. Polymorphism of the beta(2)-adrenoceptor in COPD in Chinese subjects. Chest. 2001;120(5):1493-1499.

10. Vacca G, Schwabe K, Duck R, et al. Polymorphisms of the beta2 adrenoreceptor gene in chronic obstructive pulmonary disease. Ther Adv Respir Dis. 2009;3(1):3-10.

11. Niu W, Qi Y. Matrix metalloproteinase family gene polymorphisms and risk for coronary artery disease: systematic review and meta-analysis. Heart (British Cardiac Society). 2012;98(20):1483-1491.

12. Stewart LA, Clarke M, Rovers M, et al. Preferred Reporting Items for Systematic Review and Meta-Analyses of individual participant data: the PRISMA-IPD Statement. JAMA. 2015;313(16):1657-1665.

13. Thakkinstian A, McEvoy M, Minelli C, et al. Systematic review and meta-analysis of the association between \{beta\}2-adrenoceptor polymorphisms and asthma: a HuGE review. Am J Epidemiol. 2005;162(3):201-211.

14. Attia J, Thakkinstian A, D'Este C. Meta-analyses of molecular association studies: methodologic lessons for genetic epidemiology. J Clin Epidemiol. 2003;56(4):297-303. 
15. Cohn LD, Becker BJ. How meta-analysis increases statistical power. Psychol Methods. 2003;8(3):243-253.

16. Hegab AE, Sakamoto T, Saitoh W, et al. Polymorphisms of IL4, IL13, and ADRB2 genes in COPD. Chest. 2004;126(6):1832-1839.

17. Brogger J, Steen VM, Eiken HG, Gulsvik A, Bakke P. Genetic association between COPD and polymorphisms in TNF, ADRB2 and EPHX1. Eur Respir J. 2006;27(4):682-688.

18. Matheson MC, Ellis JA, Raven J, Johns DP, Walters EH, Abramson MJ. Beta2-adrenergic receptor polymorphisms are associated with asthma and COPD in adults. Journal of human genetics. 2006;51(11):943-951.

19. Ferdinands JM, Mannino DM, Gwinn ML, Bray MS. ADRB2 Arg16Gly polymorphism, lung function, and mortality: results from the Atherosclerosis Risk in Communities study. PloS one. 2007;2(3):e289.

20. Kim WJ, Oh YM, Sung J, et al. Lung function response to 12-week treatment with combined inhalation of long-acting beta2 agonist and glucocorticoid according to ADRB2 polymorphism in patients with chronic obstructive pulmonary disease. Lung. 2008;186(6):381-386.

21. Papatheodorou A, Makrythanasis P, Kaliakatsos M, et al. Development of novel microarray methodology for the study of mutations in the SERPINA1 and ADRB2 genes--their association with Obstructive Pulmonary Disease and Disseminated Bronchiectasis in Greek patients. Clinical biochemistry. 2010;43(1-2):43-50.

22. Bleecker ER, Meyers DA, Bailey WC, et al. ADRB2 polymorphisms and budesonide/formoterol responses in COPD. Chest. 2012;142(2):320-328.

23. Marson FA, Bertuzzo CS, Ribeiro AF, Ribeiro JD. Polymorphisms in ADRB2 gene can modulate the response to bronchodilators and the severity of cystic fibrosis. BMC pulmonary medicine. 2012;12:50.

24. Thomsen M, Nordestgaard BG, Sethi AA, Tybjaerg-Hansen A, Dahl M. beta2-adrenergic receptor polymorphisms, asthma and COPD: two large population-based studies. Eur Respir J. 2012;39(3):558-566.

25. Chimedlkhamsuren Ganbold ${ }_{1}$ JJ, Odonchimeg Puntsag, Ochbadrakh Batjargalı,, Ichinnorov Dashtseren $_{2}$ SJ. ADRB2 and ACE Gene Polymorphisms in COPD Susceptibility. central Asian journal of medical science. 2016.

26. Hussein MH, Sobhy KE, Sabry IM, El Serafi AT, Toraih EA. Beta2-adrenergic receptor gene haplotypes and bronchodilator response in Egyptian patients with chronic obstructive pulmonary disease. Advances in medical sciences. 2017;62(1):193-201.

27. Zhao H, Wu X, Dong CL, Wang BY, Zhao J, Cao XE. Association Between ADRB2 Genetic Polymorphisms and the Risk of Chronic Obstructive Pulmonary Disease: A Case-Control Study in a Chinese Population. Genet Test Mol Biomarkers. 2017;21(8):491-496.

28. Li JX, Fu WP, Zhang J, et al. A functional SNP upstream of the ADRB2 gene is associated with COPD. Int J Chron Obstruct Pulmon Dis. 2018;13:917-925.

29. Pauwels RA, Buist AS, Calverley PM, Jenkins CR, Hurd SS, Committee GS. Global strategy for the diagnosis, management, and prevention of chronic obstructive pulmonary disease. NHLBI/WHO Global Initiative for Chronic Obstructive Lung Disease (GOLD) Workshop summary. Am J Respir Crit Care Med. 2001;163(5):1256-1276.

30. Standards for the diagnosis and care of patients with chronic obstructive pulmonary disease. American Thoracic Society. Am J Respir Crit Care Med. 1995;152(5 Pt 2):S77-121.

31. Wang W, Li P, Chen Y, Yang J. Association between beta2-Adrenergic Receptor-16Arg/Gly Gene Polymorphism and Chronic Obstructive Pulmonary Disease Risk:Systematic Review and Meta-Analysis. Iranian journal of public health. 2014;43(7):877-888.

32. Nielsen AO, Jensen CS, Arredouani MS, Dahl R, Dahl M. Variants of the ADRB2 Gene in COPD: Systematic Review and Meta-Analyses of Disease Risk and Treatment Response. COPD. 2017;14(4):451-460.

33. Sampsonas F, Karkoulias K, Kaparianos A, Spiropoulos K. Genetics of chronic obstructive pulmonary disease, beyond a1-antitrypsin deficiency. Curr Med Chem. 2006;13(24):2857-2873.

34. Mlak R, Homa-Mlak I, Powrozek T, et al. Impact of I/D polymorphism of ACE gene on risk of development and course of chronic obstructive pulmonary disease. Arch Med Sci. 2016;12(2):279-287.

35. Cui K, Ge XY, Ma HL. Association of the TNF-alpha+489 G/A polymorphism with chronic obstructive pulmonary disease risk in Asians: meta-analysis. Genet Mol Res. 2015;14(2):5210-5220.

36. Murdaca G, Gulli R, Spano F, et al. TNF-alpha gene polymorphisms: association with disease susceptibility and response to anti-TNF-alpha treatment in psoriatic arthritis. J Invest Dermatol. 2014;134(10):2503-2509.

37. Murdaca G, Gulli R, Spano F, Mandich P, Puppo F. Pharmacogenetics and future therapeutic scenarios: what affects the prediction of response to treatment with etanercept? Drug Dev Res. 2014;75 Suppl 1:S7-S10. 
38. Murdaca G, Spano F, Contatore M, Guastalla A, Magnani O, Puppo F. Pharmacogenetics of etanercept: role of TNF-alpha gene polymorphisms in improving its efficacy. Expert Opin Drug Metab Toxicol. 2014;10(12):1703-1710.

39. McAuley L, Pham B, Tugwell P, Moher D. Does the inclusion of grey literature influence estimates of intervention effectiveness reported in meta-analyses? Lancet. 2000;356(9237):1228-1231. 


\begin{tabular}{|c|c|c|c|c|c|c|c|c|c|c|c|c|c|c|c|c|c|}
\hline \multicolumn{4}{|c|}{ First author } & Year & Country & & Ethnicity & \multicolumn{2}{|c|}{ Sample size } & Matched condition & \multicolumn{2}{|c|}{ Study design } & COPD diagnosis & \multicolumn{2}{|c|}{ COPD stage } & \multicolumn{2}{|c|}{ Features of controls } \\
\hline \multicolumn{4}{|l|}{ Ho, L. I } & 2001 & China & & East Asian & \multicolumn{2}{|c|}{106} & YES & \multicolumn{2}{|c|}{ Prospective } & ATS & & I-III & \multicolumn{2}{|c|}{ NA } \\
\hline \multicolumn{4}{|c|}{ Hegab, A. E. (Japan) } & 2004 & Japan & & East Asian & \multicolumn{2}{|c|}{149} & YES & \multicolumn{2}{|c|}{ Retrospective } & GOLD & & I-IV & \multicolumn{2}{|c|}{ Smoke } \\
\hline \multicolumn{4}{|c|}{ Hegab, A. E. (Egypt) } & 2004 & Egypt & & African & \multicolumn{2}{|c|}{178} & YES & \multicolumn{2}{|c|}{ Retrospective } & GOLD & & I-IV & \multicolumn{2}{|c|}{ Smoke } \\
\hline \multicolumn{4}{|l|}{ Brogger, J. } & 2006 & Norway & & Caucasian & \multicolumn{2}{|c|}{492} & NA & \multicolumn{2}{|c|}{ Prospective } & GOLD & & I-IV & \multicolumn{2}{|c|}{ Smoke } \\
\hline Matheson, $\mathrm{N}$ & & & & 2006 & Australia & & Caucasian & & & NA & & & ATS & & I-III & & \\
\hline Ferdinands, & M. (American & ican) & & 2007 & America & & merican-African & & & NA & & & GOLD & & I-IV & & \\
\hline Ferdinands, & M. (Caucasiar & & & 2007 & America & & Caucasian & & & NA & & & GOLD & & I-IV & & \\
\hline Vacca, G. & & & & 2009 & German & & Caucasian & & & YES & & & GOLD & & I-IV & & \\
\hline Papatheodor & $\mathrm{u}, \mathrm{A}$. & & & 2010 & Greece & & European & & & NA & & & GOLD & & I-IV & & \\
\hline Thomsen, $\mathrm{M}$ & & & & 2012 & Denmark & & Caucasian & & & NA & & & GOLD & & I-IV & & \\
\hline Ganbold, C. & & & & 2016 & Mongolia & & Middle Asian & & & YES & & & GOLD & & I-IV & & \\
\hline Hussein, M. & & & & 2017 & Egypt & & African & & & YES & & & GOLD & & I-IV & & \\
\hline Zhao, H. & & & & 2017 & China & & East Asian & & & NA & & & GOLD & & I-IV & & \\
\hline Li, J. X. & & & & 2018 & China & & East Asian & & & YES & & & GOLD & & I-IV & & \\
\hline$\overline{\text { (Continued) }}$ & & & & & & & & & & & & & & & & & \\
\hline & & Age ( & ars) & M & & & ck-years & FEV1 & redicted $(\%)$ & & EV1 & & V1/FVC & FEV & $1 / \mathrm{FVC} \%$ & & \\
\hline Cases & Controls & Cases & Controls & Cases & Controls & Cases & Controls & Cases & Controls & Cases & Contro & Cases & Controls & Cases & Controls & Cases & Controls \\
\hline Hospital & Hospital & 71.2 & 71.2 & 60 & NA & NA & $\mathrm{NA}$ & 45.2 & NA & 45.2 & NA & NA & NA & NA & NA & NA & NA \\
\hline Population & Population & 66.9 & 67.8 & 85 & 60 & 60.1 & 53.3 & 46.7 & 96.2 & 46.7 & 96.2 & 77.4 & 97.1 & 47.1 & 81.4 & NA & NA \\
\hline Population & Population & 62.5 & 59 & 106 & 72 & 52.5 & 49.5 & 30.3 & 85.9 & 30.3 & 85.9 & 56.3 & 92.3 & 44.3 & 78.3 & NA & NA \\
\hline Hospital & Population & 58.4 & 54.9 & 144 & 128 & 28.8 & 19.1 & 50 & 95.4 & 50 & 95.4 & 76 & 97.9 & 52 & 80 & 3.16 & 4.15 \\
\hline Population & Population & 62.7 & 56.9 & 21 & 128 & 36 & 33 & 71.2 & 113.6 & 71.2 & 113.6 & 97 & 113.2 & 56.5 & 79 & 3.63 & 4.53 \\
\hline Population & Population & 54.6 & 53.5 & NA & NA & NA & NA & NA & NA & NA & NA & NA & NA & NA & NA & NA & NA \\
\hline Population & Population & 56.4 & 54.4 & NA & NA & NA & NA & NA & NA & NA & NA & NA & NA & NA & NA & NA & NA \\
\hline Hospital & Hospital & 62.66 & 65.29 & 124 & 93 & 33.52 & 25.38 & 51.31 & 94.16 & 51.31 & 94.16 & 70.87 & 98 & 57.2 & 78.78 & NA & NA \\
\hline Hospital & Hospital & 69.4 & 63 & 40 & 54 & 76.1 & 44.3 & 48.5 & 100.7 & 48.5 & 100.7 & 70.8 & 101.6 & 53 & 83 & NA & NA \\
\hline Population & Population & 59.8 & 59.8 & NA & NA & NA & NA & NA & NA & NA & NA & NA & NA & NA & NA & NA & NA \\
\hline
\end{tabular}




\begin{tabular}{|c|c|c|c|c|c|c|c|c|c|c|c|c|c|c|c|c|c|}
\hline Hospital & Hospital & 62.2 & 60.3 & 57 & 54 & 31 & 29.2 & 44.5 & 82.4 & 44.5 & 82.4 & 49.9 & 94.9 & 53 & 86 & NA & NA \\
\hline Hospital & Hospital & 62 & 60.91 & 60 & 51 & 72.9 & 30.5 & 32.9 & 91.6 & 32.9 & 91.6 & 48.6 & 86.4 & 53.2 & 85.1 & NA & NA \\
\hline Hospital & Hospital & 63.17 & 61.77 & 172 & 146 & 27.15 & 22.9 & 52.99 & 91.22 & 52.99 & 91.22 & NA & NA & 51.86 & 83.54 & NA & NA \\
\hline Hospital & Hospital & 69.9 & 67.9 & 163 & 160 & 30.6 & 28.8 & 54 & 95 & 54 & 95 & NA & NA & 49 & 86 & NA & NA \\
\hline
\end{tabular}

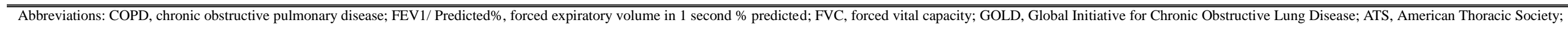
NA, not available. 
Table 2. Subsidiary association of two polymorphisms in $A D R B 2$ gene with COPD risk under both allele and dominant models.

\begin{tabular}{|c|c|c|c|c|c|c|c|c|}
\hline \multirow{2}{*}{\multicolumn{2}{|c|}{ Subgroups }} & \multirow{2}{*}{$\begin{array}{c}\text { Studies (cases/ } \\
\text { controls), } \\
\text { n (n/n) }\end{array}$} & \multicolumn{3}{|c|}{ Allele model } & \multicolumn{3}{|c|}{ Dominant model } \\
\hline & & & OR $(95 \%$ CI $)$ & $I^{2}$ & $p$ & OR $(95 \% \mathrm{CI})$ & $I^{2}$ & $p$ \\
\hline \multicolumn{9}{|l|}{ rs1042713 } \\
\hline \multicolumn{9}{|c|}{ By sample size } \\
\hline & Sample size $<164$ & $4(258 / 175)$ & $1.02(0.62$ to 1.68$)$ & $67.5 \%$ & 0.026 & $1.27(0.80$ to 2.03$)$ & $0.0 \%$ & 0.570 \\
\hline & Sample size $\geq 164$ & $9(2389 / 8398)$ & $1.03(0.87$ to 1.20$)$ & $61.9 \%$ & 0.007 & $1.07(0.82$ to 1.41$)$ & $70.4 \%$ & 0.001 \\
\hline \multicolumn{9}{|l|}{ By ethnicity } \\
\hline & African & $3(211 / 145)$ & $0.82(0.47$ to 1.41$)$ & $65.4 \%$ & 0.056 & $0.74(0.46$ to 1.17$)$ & $0.0 \%$ & 0.544 \\
\hline & Asian & $3(355 / 324)$ & $1.09(0.72$ to 1.64$)$ & $64.6 \%$ & 0.059 & 1.660 (1.13 to 2.44$)$ & $0.0 \%$ & 0.967 \\
\hline & Caucasian & $7(2081 / 8104)$ & 1.07 (0.89 to 1.30$)$ & $65.2 \%$ & 0.008 & 1.073 (0.79 to 1.46$)$ & $70.6 \%$ & 0.002 \\
\hline \multicolumn{9}{|c|}{ By study design } \\
\hline & Retrospective & $8(897 / 1019)$ & $1.09(0.85$ to 1.39$)$ & $69.0 \%$ & 0.002 & $1.06(0.71$ to 1.57$)$ & $69.6 \%$ & 0.002 \\
\hline & Prospective & $5(1750 / 7554)$ & $0.99(0.80$ to 1.21$)$ & $47.7 \%$ & 0.105 & $1.16(0.87$ to 1.55$)$ & $42.4 \%$ & 0.139 \\
\hline \multicolumn{9}{|c|}{ By matched status } \\
\hline & YES & $6(610 / 511)$ & $0.92(0.69$ to 1.22$)$ & $62.5 \%$ & 0.021 & 0.83 (0.56 to 1.2$)$ & $47.0 \%$ & 0.093 \\
\hline & NA & $7(2037 / 8062)$ & $1.13(0.93$ to 1.37$)$ & $62.3 \%$ & 0.014 & $1.33(0.99$ to 1.77$)$ & $61.8 \%$ & 0.015 \\
\hline \multicolumn{9}{|c|}{ By COPD diagnosis } \\
\hline & ATS & $2(104 / 262)$ & $1.21(0.42$ to 3.53$)$ & $88.0 \%$ & 0.004 & $2.17(1.14$ to 4.12$)$ & $0.0 \%$ & 0.389 \\
\hline & GOLD & $11(2543 / 8311)$ & $1.01(0.88$ to 1.16$)$ & $51.2 \%$ & 0.025 & $1.03(0.81$ to 1.29$)$ & $57.8 \%$ & 0.008 \\
\hline \multicolumn{9}{|c|}{ By case source } \\
\hline & Hospital & $7(967 / 945)$ & $0.99(0.84$ to 1.15$)$ & $28.3 \%$ & 0.212 & $1.02(0.73$ to 1.42$)$ & $59.0 \%$ & 0.023 \\
\hline & Population & $6(1680 / 7628)$ & $1.13(0.80$ to 1.60$)$ & $77.9 \%$ & $<0.0001$ & $1.24(0.81$ to 1.92$)$ & $67.4 \%$ & 0.009 \\
\hline \multicolumn{9}{|c|}{ By control source } \\
\hline & Hospital & $6(729 / 706)$ & $0.95(0.79$ to 1.15$)$ & $31.2 \%$ & 0.201 & $0.99(0.64$ to 1.46$)$ & $61.8 \%$ & 0.023 \\
\hline & Population & $7(1918 / 7867)$ & $1.13(0.87$ to 1.46$)$ & $74.3 \%$ & 0.001 & $1.23(0.88$ to 1.70$)$ & $63.9 \%$ & 0.011 \\
\hline \multicolumn{9}{|l|}{ rs1042714 } \\
\hline \multicolumn{9}{|c|}{ By sample size } \\
\hline & Sample size $<164$ & $3(213 / 156)$ & $0.93(0.45$ to 1.89$)$ & $65.2 \%$ & 0.056 & $0.88(0.26$ to 2.93$)$ & $81.7 \%$ & 0.004 \\
\hline & Sample size $\geq 164$ & $9(2536 / 8591)$ & 1.07 (0.89 to 1.27$)$ & $67.6 \%$ & 0.002 & 1.07 (0.84 to 1.37$)$ & $67.0 \%$ & 0.002 \\
\hline
\end{tabular}




\begin{tabular}{|c|c|c|c|c|c|c|c|c|}
\hline By ethnicity & & & & & & & & \\
\hline & African & $2(167 / 126)$ & $1.20(0.27$ to 5.44$)$ & $93.2 \%$ & $<0.0001$ & $0.98(0.09$ to 10.35$)$ & $95.3 \%$ & $<0.0001$ \\
\hline & Asian & $4(613 / 563)$ & $1.27(0.92$ to 1.73$)$ & $28.8 \%$ & 0.239 & $1.35(1.02$ to 1.79$)$ & $1.7 \%$ & 0.384 \\
\hline & Caucasian & $6(1969 / 8058)$ & $0.95(0.81$ to 1.11$)$ & $50.8 \%$ & 0.071 & $0.89(0.71$ to 1.13$)$ & $49.1 \%$ & 0.081 \\
\hline \multicolumn{9}{|c|}{ By study design } \\
\hline & Retrospective & $9(1187 / 1247)$ & $1.08(0.81$ to 1.45$)$ & $74.1 \%$ & $<0.0001$ & $1.03(0.68$ to 1.56$)$ & $78.1 \%$ & $<0.0001$ \\
\hline & Prospective & $3(1562 / 7500)$ & $1.05(0.97$ to 1.13$)$ & $0.0 \%$ & 0.482 & $1.09(0.96$ to 1.23$)$ & $0.0 \%$ & 0.661 \\
\hline \multicolumn{9}{|c|}{ By matched status } \\
\hline & YES & $8(609 / 500)$ & $1.041(0.655$ to 1.655$)$ & $79.1 \%$ & $<0.0001$ & 0.977 (0.494 to 1.932$)$ & $83.5 \%$ & $<0.0001$ \\
\hline & NA & $4(2140 / 8247)$ & $1.054(0.919$ to 1.210$)$ & $35.6 \%$ & 0.170 & $1.100(0.965$ to 1.254$)$ & $6.7 \%$ & 0.374 \\
\hline \multicolumn{9}{|c|}{ By COPD diagnosis } \\
\hline & ATS & $2(138 / 262)$ & $0.78(0.57$ to 1.08$)$ & $0.0 \%$ & 0.741 & $0.82(0.52$ to 1.31$)$ & $0.0 \%$ & 0.549 \\
\hline & GOLD & $10(2611 / 8485)$ & $1.08(0.89$ to 1.31$)$ & $69.0 \%$ & 0.001 & $1.05(0.79$ to 1.40$)$ & $75.0 \%$ & $<0.0001$ \\
\hline \multicolumn{9}{|c|}{ By case source } \\
\hline & Hospital & $8(1230 / 1179)$ & $0.96(0.78$ to 1.18$)$ & $54.3 \%$ & 0.032 & $0.87(0.63$ to 1.20$)$ & $65.5 \%$ & 0.005 \\
\hline & Population & $4(1519 / 7568)$ & $1.32(0.83$ to 2.10$)$ & $80.7 \%$ & 0.001 & $1.48(0.82$ to 2.65$)$ & $78.6 \%$ & 0.003 \\
\hline \multicolumn{9}{|c|}{ By control source } \\
\hline & Hospital & $7(986 / 934)$ & $0.96(0.75$ to 1.24$)$ & $60.3 \%$ & 0.019 & $0.85(0.58$ to 1.26$)$ & $70.4 \%$ & 0.002 \\
\hline & Population & $5(1763 / 7813)$ & $1.15(0.86$ to 1.55$)$ & $76.1 \%$ & 0.002 & $1.27(0.85$ to 1.90$)$ & $73.4 \%$ & 0.005 \\
\hline
\end{tabular}

Abbreviations: OR, odds ratio; 95\% CI, 95\% confidence interval; $I^{2}$, inconsistence index; NA, not available. 
Table 3. Overall and subgroup analyses of $A D R B 2$ gene polymorphisms with COPD-related phenotypes.

\section{rs1042713}

\begin{tabular}{|c|c|c|c|c|c|c|c|c|c|c|}
\hline \multirow[t]{2}{*}{ Groups } & \multicolumn{5}{|c|}{ AA vs. GG } & \multicolumn{5}{|c|}{ AG vs. GG } \\
\hline & Studies (total samples), n (n) & WMD & $95 \% \mathrm{CI}$ & $I^{2}$ & $p$ & Studies (total samples), n (n) & WMD & $95 \% \mathrm{CI}$ & $I^{2}$ & $p$ \\
\hline FEV1 (L) (Overall) & $4(1625)$ & -0.011 & -0.026 to -0.004 & $0.0 \%$ & 0.767 & $4(2550)$ & 0.007 & -0.016 to 0.030 & $0.0 \%$ & 0.786 \\
\hline \multicolumn{11}{|l|}{ FEV1 (L) by ethnicity } \\
\hline Asian & $2(79)$ & -0.095 & -0.322 to 0.132 & $0.0 \%$ & 0.477 & $2(122)$ & 0.038 & -0.150 to 0.226 & $0.0 \%$ & 0.564 \\
\hline Mixed & $2(1546)$ & -0.011 & -0.026 to 0.004 & $0.0 \%$ & 0.738 & $2(2428)$ & 0.006 & -0.017 to 0.030 & $0.0 \%$ & 0.429 \\
\hline \multicolumn{11}{|l|}{ FEV1 (L) by group } \\
\hline FEV1\% predicted (Overall) & $8(9383)$ & 0.991 & -0.602 to 2.583 & $70.8 \%$ & 0.001 & $8(15095)$ & 1.175 & -0.515 to 2.866 & $86.6 \%$ & 0.000 \\
\hline \multicolumn{11}{|l|}{ FEV1\%predicted by ethnicity } \\
\hline Asian & $1(17)$ & -12.0 & -32.927 to 8.927 & NA & NA & $1(56)$ & 1.000 & -19.852 to 21.852 & NA & NA \\
\hline African & $2(2039)$ & 10.396 & -12.912 to 33.705 & $86.3 \%$ & 0.007 & $2(3045)$ & 0.108 & -1.662 to 1.878 & $0.0 \%$ & 0.537 \\
\hline Caucasian & $2(5781)$ & 2.466 & -2.156 to 7.087 & $85.7 \%$ & 0.001 & $3(9566)$ & 1.896 & -3.152 to 6.943 & $95.8 \%$ & $<0.0001$ \\
\hline Mixed & $2(1546)$ & 0.044 & -0.995 to 1.083 & $0.0 \%$ & 0.777 & $2(2428)$ & 0.284 & -0.500 to 1.067 & $9.3 \%$ & 0.294 \\
\hline \multicolumn{11}{|l|}{ FEV $1 \%$ predicted by group } \\
\hline COPD patients & $5(1692)$ & 0.415 & -1.959 to 2.789 & $54.7 \%$ & 0.066 & $5(2698)$ & 0.279 & -0.461 to 1.018 & $0.0 \%$ & 0.778 \\
\hline Controls & $1(67)$ & 0.000 & -0.949 to 0.949 & $0.0 \%$ & 1.00 & $2(12300)$ & 0.000 & -0.657 to 0.657 & $0.0 \%$ & 1.000 \\
\hline Both & $2(7624)$ & 5.360 & 2.781 to 7.939 & NA & NA & $1(97)$ & 5.930 & 4.400 to 7.460 & NA & NA \\
\hline FVC\% predicted (Overall) & $2(84)$ & 6.914 & 4.829 to 8.999 & $0.0 \%$ & 0.414 & $2(154)$ & 4.249 & 2.925 to 5.573 & $0.0 \%$ & 0.982 \\
\hline \multicolumn{11}{|l|}{ FVC\% predicted by ethnicity } \\
\hline Asian & $1(17)$ & -3.00 & -26.884 to 20.884 & NA & NA & $1(56)$ & 4.000 & -17.783 to 25.783 & NA & NA \\
\hline Caucasian & $1(67)$ & 6.990 & 4.897 to 9.083 & NA & NA & $1(98)$ & 4.250 & 2.923 to 5.577 & NA & NA \\
\hline \multicolumn{11}{|l|}{ FVC\% predicted by group } \\
\hline COPD patients & $1(17)$ & 0.415 & -1.959 to 2.789 & $54.7 \%$ & 0.066 & $1(56)$ & 4.000 & -17.783 to 25.783 & NA & NA \\
\hline Both & $1(67)$ & 5.360 & 2.781 to 7.939 & NA & NA & $1(98)$ & 4.250 & 2.923 to 5.577 & NA & NA \\
\hline FEV1/FVC (\%) & $6(7837)$ & -0.144 & -0.993 to 0.706 & $37.2 \%$ & 0.158 & $6(12666)$ & 0.373 & -0.296 to 1.043 & $45.6 \%$ & 0.102 \\
\hline \multicolumn{11}{|l|}{ FEV1/FVC (\%) by ethnicity } \\
\hline Asian & $1(17)$ & -12.000 & -27.090 to 3.090 & NA & NA & $1(56)$ & -1.000 & -14.368 to 12.368 & NA & NA \\
\hline
\end{tabular}




\begin{tabular}{|c|c|c|c|c|c|c|c|c|c|c|}
\hline African & $2(2039)$ & 3.258 & -5.219 to 11.735 & $72.1 \%$ & 0.058 & $2(3045)$ & 0.010 & -0.674 to 0.695 & $0.0 \%$ & 0.773 \\
\hline Caucasian & $3(5781)$ & -0.162 & -0.846 to 0.523 & $0.0 \%$ & 0.407 & $3(9565)$ & 0.558 & -0.738 to 1.854 & $76.2 \%$ & 0.015 \\
\hline \multicolumn{11}{|l|}{ FEV1/FVC (\%) by group } \\
\hline COPD patients & $3(146)$ & 0.917 & -8.278 to 10.112 & $64.2 \%$ & 0.061 & $3(270)$ & -0.433 & -4.041 to 3.176 & $0.0 \%$ & 0.887 \\
\hline Controls & $2(7624)$ & 0.000 & -0.508 to 0.508 & $0.0 \%$ & 1.000 & $2(12300)$ & 0.000 & -0.406 to 0.406 & $0.0 \%$ & 1.000 \\
\hline Both & $1(67)$ & -1.330 & -3.218 to 0.558 & NA & NA & $1(96)$ & 1.460 & 0.586 to 2.334 & NA & NA \\
\hline \multicolumn{11}{|l|}{ (Continued) } \\
\hline \multirow{3}{*}{ Groups } & \multicolumn{10}{|c|}{ rs1042714 } \\
\hline & \multicolumn{5}{|c|}{ CC vs. GG } & \multicolumn{5}{|c|}{ CG vs. GG } \\
\hline & Studies (total samples), n (n) & WMD & $95 \% \mathrm{CI}$ & $I^{2}$ & $p$ & Studies (total samples), n (n) & WMD & $95 \% \mathrm{CI}$ & $I^{2}$ & $p$ \\
\hline FEV1 (L) (Overall) & $2(130)$ & -0.091 & -0.40 to 0.218 & $12.7 \%$ & 0.284 & $2(49)$ & -0.058 & -0.355 to 0.240 & $0.0 \%$ & 0.562 \\
\hline \multicolumn{11}{|l|}{ FEV1 (L) by ethnicity } \\
\hline Asian & $2(130)$ & -0.091 & -0.400 to 0.218 & $12.7 \%$ & 0.284 & $2(49)$ & -0.058 & -0.355 to 0.240 & $0.0 \%$ & 0.562 \\
\hline \multicolumn{11}{|l|}{ FEV1 (L) by group } \\
\hline COPD patients & $2(130)$ & -0.091 & -0.400 to 0.218 & $12.7 \%$ & 0.284 & $2(49)$ & -0.058 & -0.355 to 0.240 & $0.0 \%$ & 0.562 \\
\hline FEV1\% predicted (Overall) & $3(325)$ & -10.003 & -27.128 to 7.122 & $87 \%$ & 0.000 & $3(142)$ & 1.906 & -2.654 to 6.466 & $0.0 \%$ & 0.583 \\
\hline \multicolumn{11}{|l|}{ FEV1\% predicted by ethnicity } \\
\hline Asian & $2(253)$ & -17.615 & -37.387 to 2.158 & $75.1 \%$ & 0.045 & $2(84)$ & -3.001 & -13.491 to 7.488 & $0.0 \%$ & 0.838 \\
\hline Caucasian & $1(72)$ & 2.640 & -2.394 to 7.674 & NA & NA & $1(58)$ & 3.050 & -2.014 to 8.114 & NA & NA \\
\hline \multicolumn{11}{|l|}{ FEV1\% predicted by group } \\
\hline COPD patients & $2(253)$ & -17.615 & -37.387 to 2.158 & $75.1 \%$ & 0.045 & $1(84)$ & -3.001 & -13.491 to 7.488 & $0.0 \%$ & 0.838 \\
\hline Both & $1(72)$ & 2.640 & -2.394 to 7.674 & NA & NA & $1(58)$ & 3.050 & -2.014 to 8.114 & NA & NA \\
\hline FVC\% predicted (Overall) & $2(118)$ & -3.017 & -13.136 to 7.102 & $63.3 \%$ & 0.099 & $2(85)$ & -1.042 & -9.909 to 7.826 & $50.4 \%$ & 0.156 \\
\hline \multicolumn{11}{|l|}{ FVC\% predicted by ethnicity } \\
\hline Asian & $1(45)$ & -10.000 & -22.165 to 2.165 & NA & NA & $1(27)$ & -8.000 & -21.030 to 5.30 & NA & NA \\
\hline Caucasian & $1(73)$ & 0.800 & -3.280 to 4.880 & NA & NA & $1(58)$ & 1.900 & -2.228 to 6.028 & NA & NA \\
\hline \multicolumn{11}{|l|}{ FVC\% predicted by group } \\
\hline COPD patients & $1(45)$ & -10.000 & -22.165 to 2.165 & NA & NA & $1(27)$ & -8.000 & -21.030 to 5.30 & NA & NA \\
\hline Both & $1(73)$ & 0.800 & -3.280 to 4.880 & NA & NA & $1(58)$ & 1.900 & -2.228 to 6.028 & NA & NA \\
\hline FEV1/FVC (\%) (Overall) & $3(325)$ & 3.098 & 0.102 to 6.095 & $0.0 \%$ & 0.634 & $3(141)$ & 0.122 & -2.912 to 3.157 & $0.0 \%$ & 0.819 \\
\hline
\end{tabular}


FEV1/FVC (\%) by ethnicity

\begin{tabular}{|c|c|c|c|c|c|c|c|c|c|c|}
\hline Asian & $2(253)$ & 2.820 & -8.342 to 13.982 & $0.0 \%$ & 0.341 & $2(84)$ & 1.516 & -9.589 to 12.620 & $0.0 \%$ & 0.563 \\
\hline Caucasian & $1(72)$ & 3.120 & 0.010 to 6.230 & $\mathrm{NA}$ & NA & $1(57)$ & 0.010 & -3.145 to 3.165 & NA & NA \\
\hline \multicolumn{11}{|l|}{ FEV1/FVC (\%) by group } \\
\hline COPD patients & $2(253)$ & 2.820 & -8.342 to 13.982 & $0.0 \%$ & 0.341 & $2(84)$ & 1.516 & -9.589 to 12.620 & $0.0 \%$ & 0.563 \\
\hline Both & $1(72)$ & 3.120 & 0.010 to 6.230 & NA & NA & $1(57)$ & 0.010 & -3.145 to 3.165 & NA & NA \\
\hline
\end{tabular}

Abbreviations: OR, odds ratio; 95\% CI, 95\% confidence interval; $I^{2}$, inconsistence index; NA, not available. 


\section{Supplementary Table 1. The PRISMA checklist for this present meta-analysis.}

\begin{tabular}{|c|c|c|c|}
\hline Section/topic & $\#$ & Checklist item & $\begin{array}{l}\text { Reported } \\
\text { on page \# }\end{array}$ \\
\hline \multicolumn{4}{|l|}{ TITLE } \\
\hline Title & 1 & Identify the report as a systematic review, meta-analysis, or both. & 1 \\
\hline \multicolumn{4}{|l|}{ ABSTRACT } \\
\hline Structured summary & 2 & $\begin{array}{l}\text { Provide a structured summary including, as applicable: background; objectives; data sources; study } \\
\text { eligibility criteria, participants, and interventions; study appraisal and synthesis methods; results; } \\
\text { limitations; conclusions and implications of key findings; systematic review registration number. }\end{array}$ & 2 \\
\hline \multicolumn{4}{|l|}{ INTRODUCTION } \\
\hline Rationale & 3 & Describe the rationale for the review in the context of what is already known. & 3 \\
\hline Objectives & 4 & $\begin{array}{l}\text { Provide an explicit statement of questions being addressed with reference to participants, interventions, } \\
\text { comparisons, outcomes, and study design (PICOS). }\end{array}$ & $3-4$ \\
\hline \multicolumn{4}{|l|}{ METHODS } \\
\hline Protocol and registration & 5 & $\begin{array}{l}\text { Indicate if a review protocol exists, if and where it can be accessed (e.g., Web address), and, if available, } \\
\text { provide registration information including registration number. }\end{array}$ & 4 \\
\hline Eligibility criteria & 6 & $\begin{array}{l}\text { Specify study characteristics (e.g., PICOS, length of follow-up) and report characteristics (e.g., years } \\
\text { considered, language, publication status) used as criteria for eligibility, giving rationale. }\end{array}$ & $4-5$ \\
\hline Information sources & 7 & $\begin{array}{l}\text { Describe all information sources (e.g., databases with dates of coverage, contact with study authors to } \\
\text { identify additional studies) in the search and date last searched. }\end{array}$ & $4-5$ \\
\hline Search & 8 & $\begin{array}{l}\text { Present full electronic search strategy for at least one database, including any limits used, such that it could } \\
\text { be repeated. }\end{array}$ & 4 \\
\hline Study selection & 9 & $\begin{array}{l}\text { State the process for selecting studies (i.e., screening, eligibility, included in systematic review, and, if } \\
\text { applicable, included in the meta-analysis). }\end{array}$ & $4-6$ \\
\hline Data collection process & 10 & $\begin{array}{l}\text { Describe method of data extraction from reports (e.g., piloted forms, independently, in duplicate) and any } \\
\text { processes for obtaining and confirming data from investigators. }\end{array}$ & 6 \\
\hline Data items & 11 & $\begin{array}{l}\text { List and define all variables for which data were sought (e.g., PICOS, funding sources) and any } \\
\text { assumptions and simplifications made. }\end{array}$ & $6-7$ \\
\hline $\begin{array}{l}\text { Risk of bias in individual } \\
\text { studies }\end{array}$ & 12 & $\begin{array}{l}\text { Describe methods used for assessing risk of bias of individual studies (including specification of whether } \\
\text { this was done at the study or outcome level), and how this information is to be used in any data synthesis. }\end{array}$ & $6-7$ \\
\hline Summary measures & 13 & State the principal summary measures (e.g., risk ratio, difference in means). & $6-7$ \\
\hline Synthesis of results & 14 & $\begin{array}{l}\text { Describe the methods of handling data and combining results of studies, if done, including measures of } \\
\text { consistency }\left(\text { e.g., } I^{2}\right) \text { for each meta-analysis. }\end{array}$ & $6-7$ \\
\hline
\end{tabular}




\begin{tabular}{|c|c|c|c|}
\hline Section/topic & \# & Checklist item & $\begin{array}{l}\text { Reported on page } \\
\#\end{array}$ \\
\hline Risk of bias across studies & 15 & $\begin{array}{l}\text { Specify any assessment of risk of bias that may affect the cumulative evidence (e.g., publication } \\
\text { bias, selective reporting within studies). }\end{array}$ & $6-7$ \\
\hline Additional analyses & 16 & $\begin{array}{l}\text { Describe methods of additional analyses (e.g., sensitivity or subgroup analyses, meta-regression), if } \\
\text { done, indicating which were pre-specified. }\end{array}$ & $6-7$ \\
\hline \multicolumn{4}{|l|}{ RESULTS } \\
\hline Study selection & 17 & $\begin{array}{l}\text { Give numbers of studies screened, assessed for eligibility, and included in the review, with reasons } \\
\text { for exclusions at each stage, ideally with a flow diagram. }\end{array}$ & Figure 1 \\
\hline Study characteristics & 18 & $\begin{array}{l}\text { For each study, present characteristics for which data were extracted (e.g., study size, PICOS, } \\
\text { follow-up period) and provide the citations. }\end{array}$ & $\begin{array}{l}7 ; 14-15 \\
\text { Table } 1\end{array}$ \\
\hline $\begin{array}{l}\text { Risk of bias within } \\
\text { studies }\end{array}$ & 19 & $\begin{array}{l}\text { Present data on risk of bias of each study and, if available, any outcome level assessment (see item } \\
\text { 12). }\end{array}$ & Figure 3 \\
\hline $\begin{array}{l}\text { Results of individual } \\
\text { studies }\end{array}$ & 20 & $\begin{array}{l}\text { For all outcomes considered (benefits or harms), present, for each study: (a) simple summary data } \\
\text { for each intervention group (b) effect estimates and confidence intervals, ideally with a forest plot. }\end{array}$ & Figure 2 \\
\hline Synthesis of results & 21 & $\begin{array}{l}\text { Present results of each meta-analysis done, including confidence intervals and measures of } \\
\text { consistency. }\end{array}$ & $7-9$ \\
\hline Risk of bias across studies & 22 & Present results of any assessment of risk of bias across studies (see Item 15). & Figure 4 \\
\hline Additional analysis & 23 & $\begin{array}{l}\text { Give results of additional analyses, if done (e.g., sensitivity or subgroup analyses, meta-regression } \\
\text { [see Item 16]). }\end{array}$ & $\begin{array}{l}\text { 7-9;16-20 } \\
\text { Supplementary } \\
\text { Figure1, Table2, } \\
\text { Table 3, Figure4 }\end{array}$ \\
\hline \multicolumn{4}{|l|}{ DISCUSSION } \\
\hline Summary of evidence & 24 & $\begin{array}{l}\text { Summarize the main findings including the strength of evidence for each main outcome; consider } \\
\text { their relevance to key groups (e.g., healthcare providers, users, and policy makers). }\end{array}$ & $9-11$ \\
\hline Limitations & 25 & $\begin{array}{l}\text { Discuss limitations at study and outcome level (e.g., risk of bias), and at review-level (e.g., } \\
\text { incomplete retrieval of identified research, reporting bias). }\end{array}$ & 11 \\
\hline Conclusions & 26 & $\begin{array}{l}\text { Provide a general interpretation of the results in the context of other evidence, and implications for } \\
\text { future research. }\end{array}$ & 11 \\
\hline \multicolumn{4}{|l|}{ FUNDING } \\
\hline Funding & 27 & $\begin{array}{l}\text { Describe sources of funding for the systematic review and other support (e.g., supply of data); role } \\
\text { of funders for the systematic review. }\end{array}$ & 12 \\
\hline
\end{tabular}


Supplementary Table 2. The quality scores of all involved studies in this present meta-analysis.

\begin{tabular}{|c|c|c|c|c|c|c|c|c|c|}
\hline First author(year) & $\begin{array}{c}\text { Representativeness } \\
\text { of cases }\end{array}$ & $\begin{array}{c}\text { Representativeness } \\
\text { of controls }\end{array}$ & $\begin{array}{c}\text { Ascertainment } \\
\text { of COPD }\end{array}$ & $\begin{array}{c}\text { Ascertainment } \\
\text { of controls }\end{array}$ & $\begin{array}{l}\text { Genotyping } \\
\text { examination }\end{array}$ & $\begin{array}{c}\text { Hardy-Weinberg } \\
\text { equilibrium }\end{array}$ & $\begin{array}{l}\text { Association } \\
\text { assessment }\end{array}$ & $\begin{array}{c}\text { Response } \\
\text { rate }\end{array}$ & Total \\
\hline Ho, L. I(2001) & 2 & 2 & 2 & 1 & 0 & 0 & 1 & 2 & 10 \\
\hline Hegab, A. E. (Japan) (2004) & 2 & 2 & 2 & 0 & 0 & 2 & 1 & 2 & 11 \\
\hline Hegab, A. E. (Egypt) (2004) & 2 & 2 & 2 & 0 & 0 & 2 & 1 & 2 & 11 \\
\hline Brogger, J.(2006) & 2 & 2 & 2 & 2 & 0 & 2 & 2 & 0 & 12 \\
\hline Matheson, M. C. (2006) & 2 & 2 & 2 & 2 & 1 & 2 & 2 & 2 & 15 \\
\hline $\begin{array}{l}\text { Ferdinands, J. M. (2007) } \\
\text { (American-African) }\end{array}$ & 2 & 2 & 2 & 2 & 1 & 2 & 2 & 2 & 15 \\
\hline $\begin{array}{l}\text { Ferdinands, J. M. (2007) } \\
\text { (Caucasian) }\end{array}$ & 2 & 2 & 2 & 2 & 1 & 2 & 2 & 2 & 15 \\
\hline Vacca, G.(2009) & 2 & 2 & 2 & 2 & 0 & 2 & 1 & 2 & 13 \\
\hline Papatheodorou, A. (2010) & 2 & 2 & 2 & 1 & 0 & 2 & 1 & 2 & 12 \\
\hline Thomsen, M.(2012) & 2 & 2 & 2 & 2 & 1 & 2 & 2 & 2 & 15 \\
\hline Ganbold, C.(2016) & 2 & 2 & 2 & 1 & 0 & 2 & 2 & 2 & 13 \\
\hline Hussein, M. H.(2017) & 2 & 2 & 2 & 1 & 0 & 2 & 2 & 2 & 13 \\
\hline Zhao, H.(2017) & 2 & 2 & 2 & 2 & 0 & 2 & 1 & 2 & 13 \\
\hline Li, J. X.(2018) & 2 & 2 & 2 & 2 & 0 & 2 & 2 & 2 & 14 \\
\hline
\end{tabular}


Supplementary Figure 1. Cumulative and influential plots of three polymorphisms in ADRB2 gene associated with the risk of chronic obstructive pulmonary disease.

A. rs 1042713

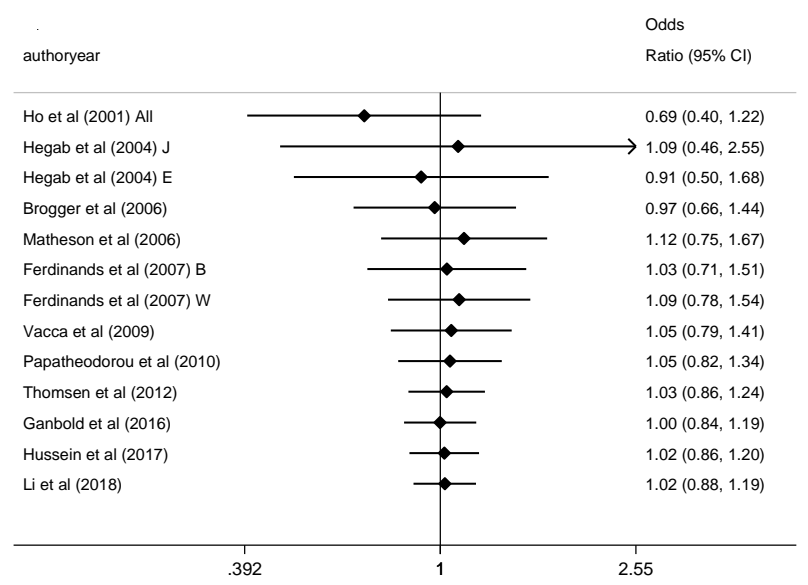

C. $\operatorname{rs} 1042714$

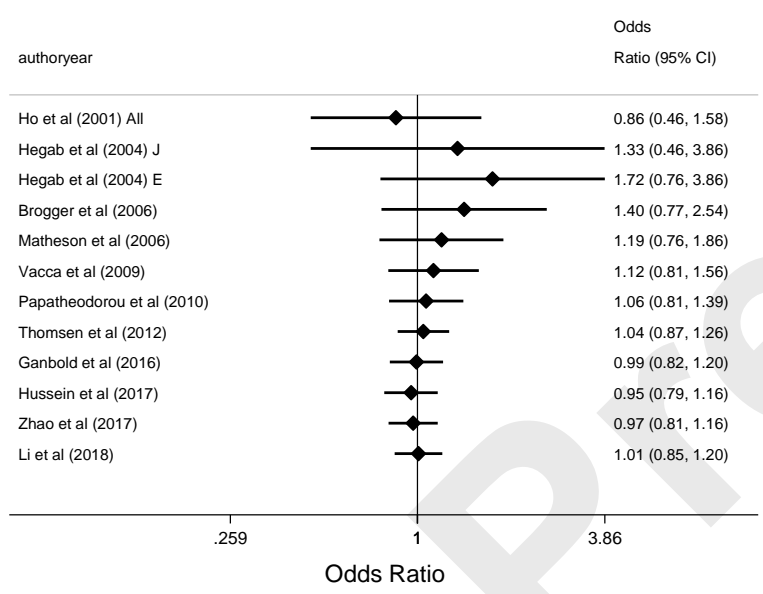

E. $r s 1800888$

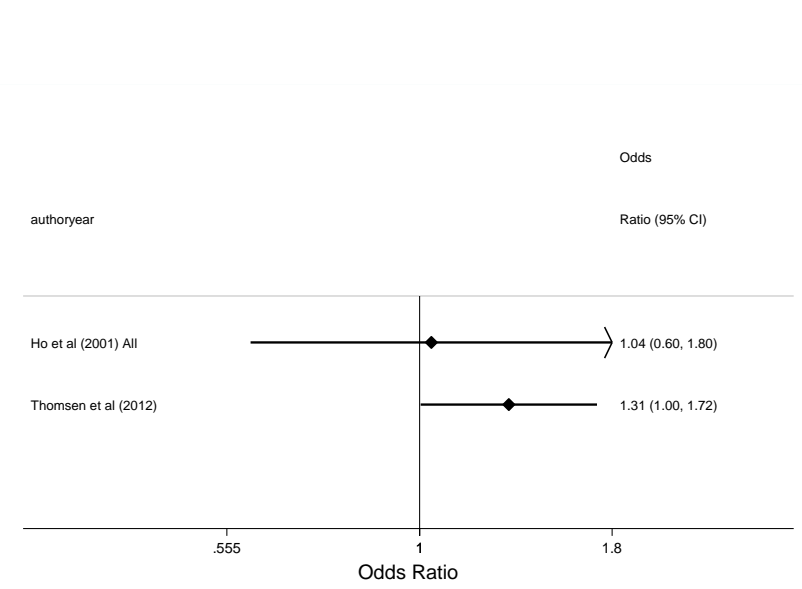

B. rs 1042713
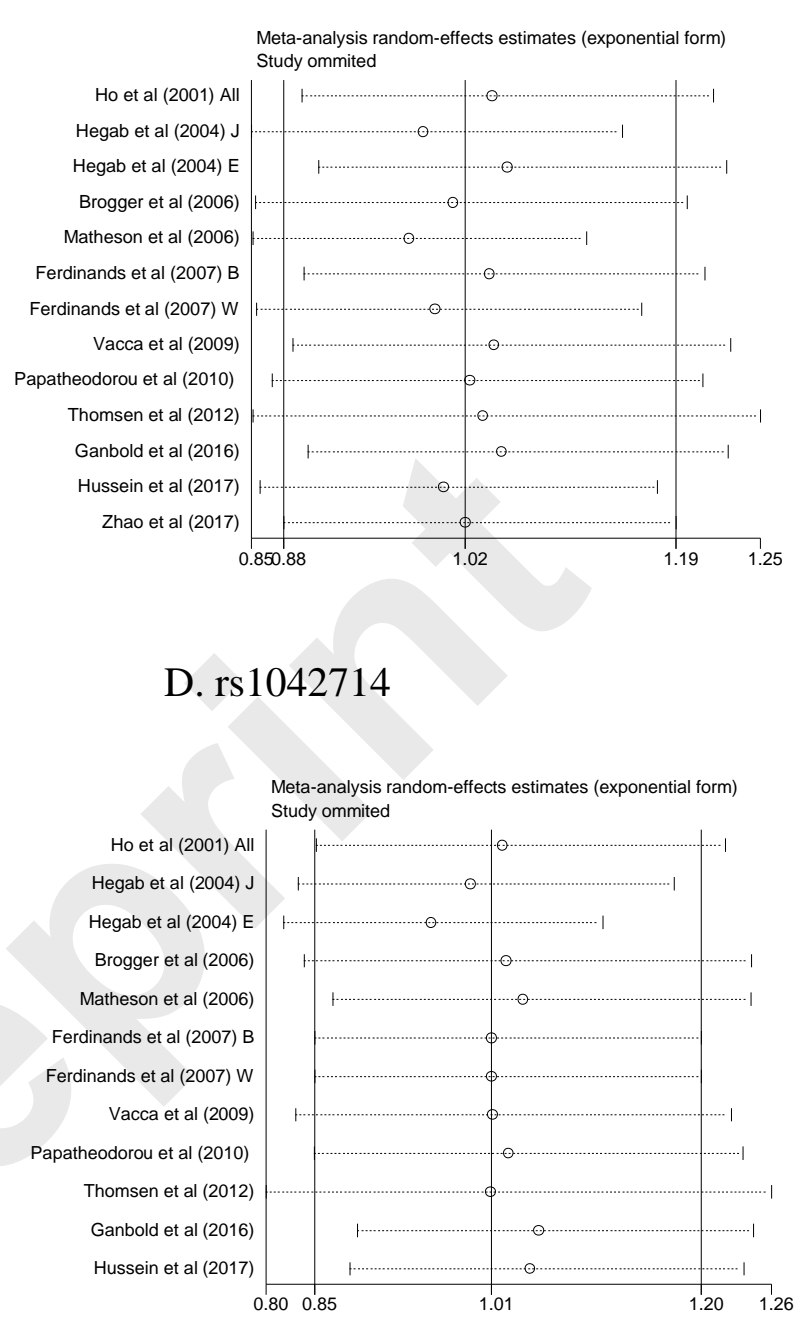

F. $r s 1800888$

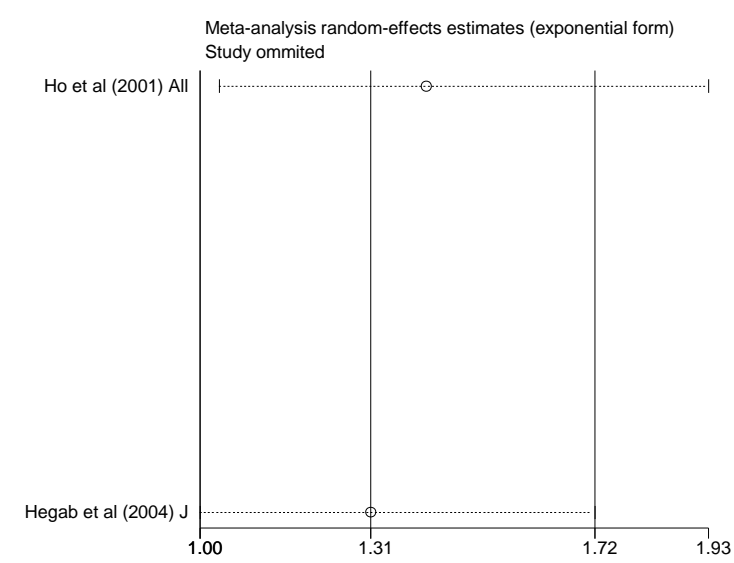




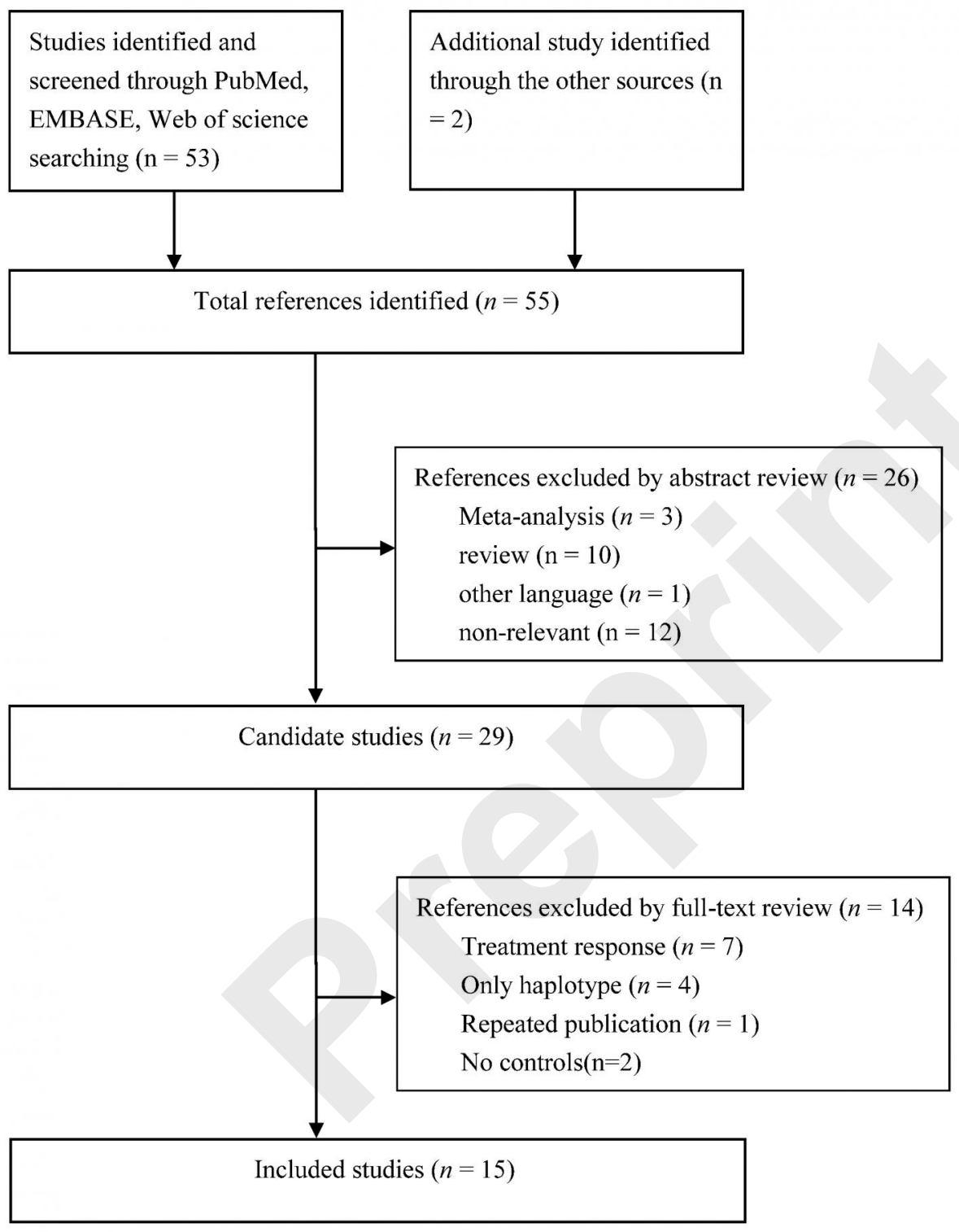


Figure 2. Forest plots of three polymorphisms in $A D R B 2$ associated with COPD under the allele model.

A. rs1042713

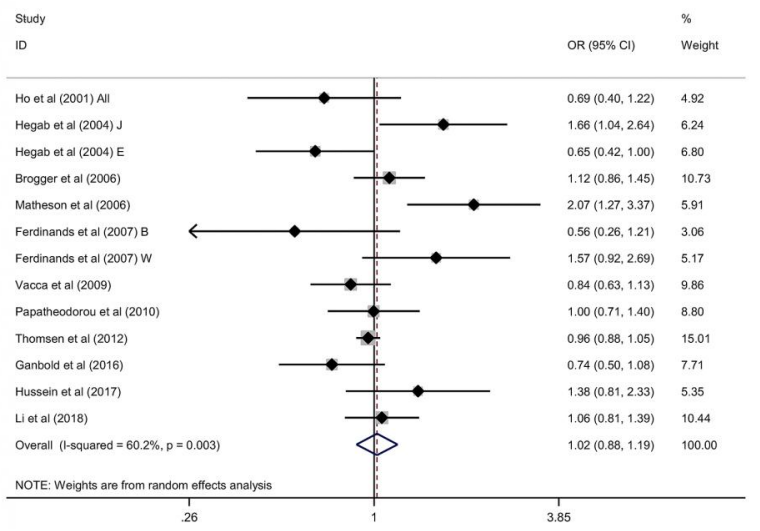

B. rs 1042714

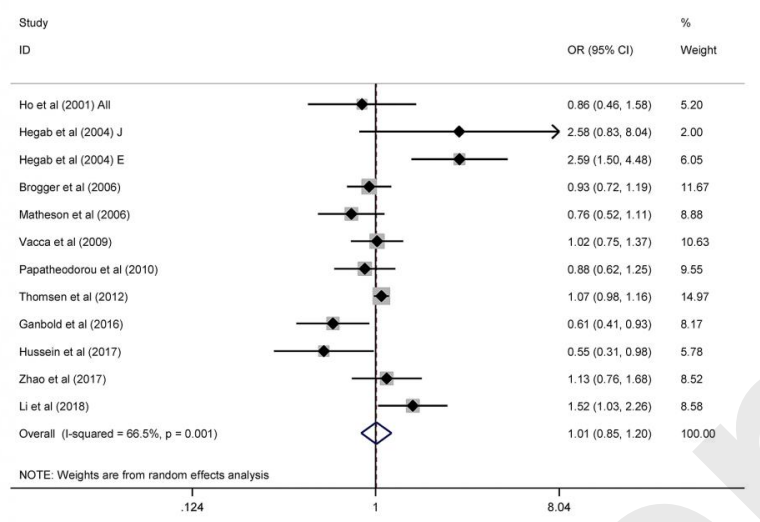

C. rs 1800888

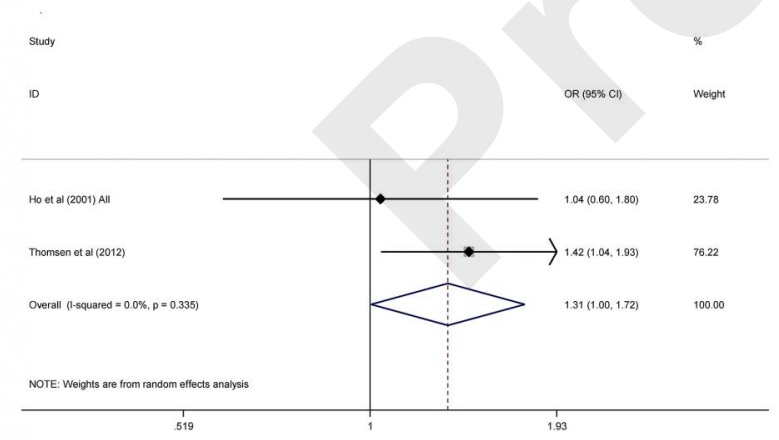


Figure 3. Begg's and filled funnel plots of three polymorphisms in $A D R B 2$ gene associated with COPD under the allele model.

A. rs1042713 Begg's funnel plot

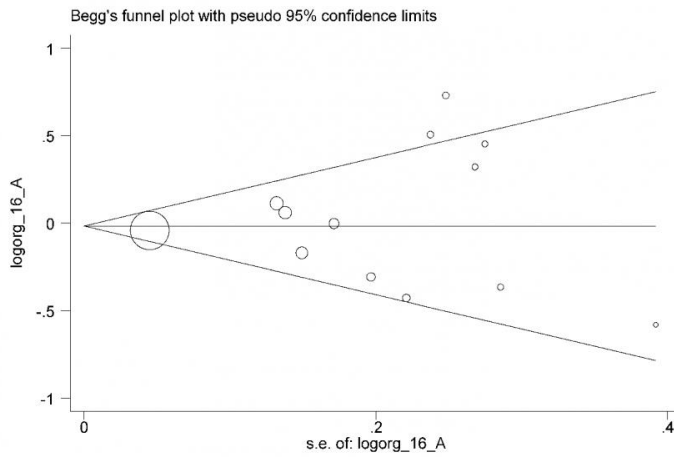

C. rs1042714 Begg's funnel plot

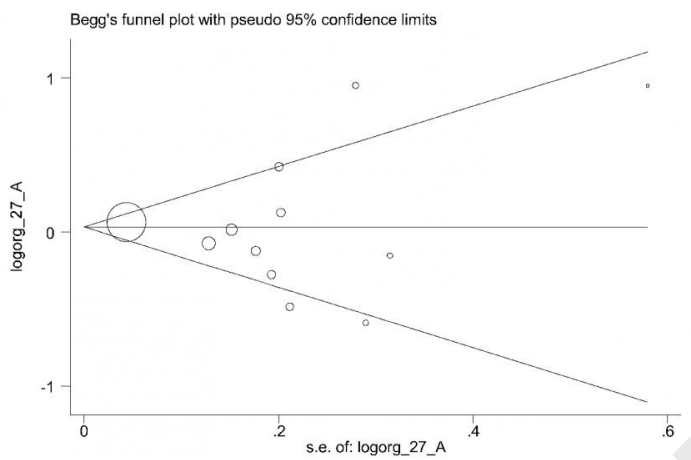

E. rs1800888 Begg's funnel plot

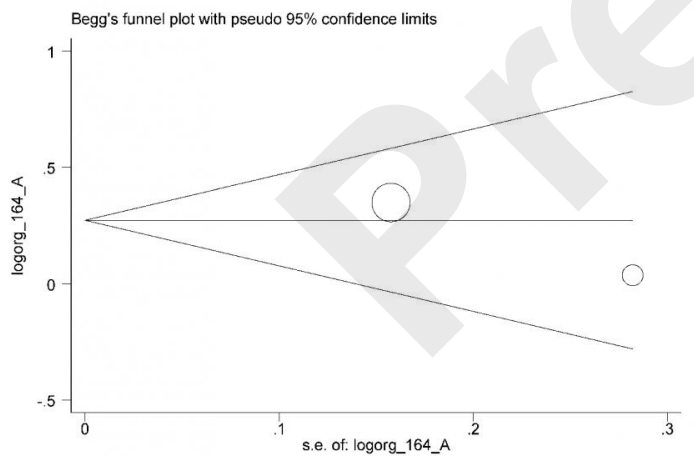

B. rs 1042713 filled funnel plot

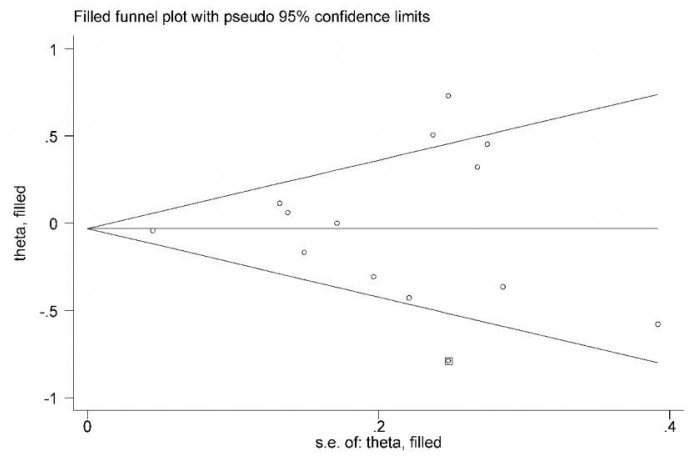

D. rs1042714 filled funnel plot

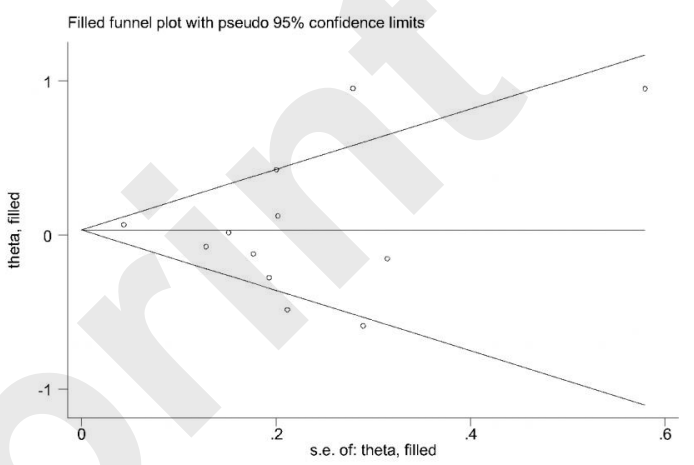

F. rs1800888 filled funnel plot

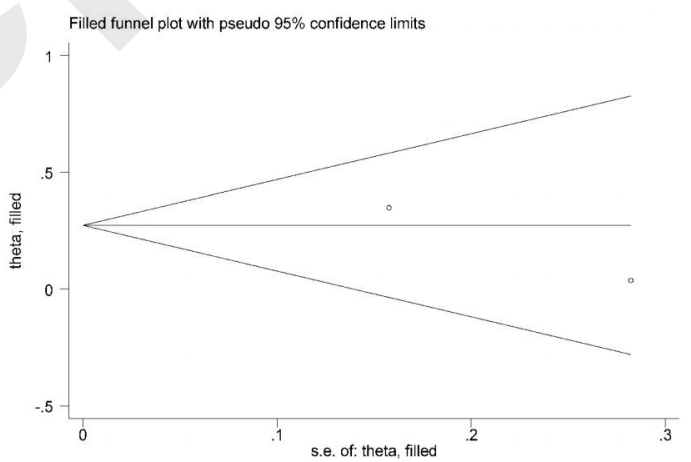


Figure 4. Meta-regression analyses of rs1042713 and rs1042714 polymorphisms in $A D R B 2$ with COPD-relevant phenotypes.

A. Average FEV1\%Pred by rs 1042713

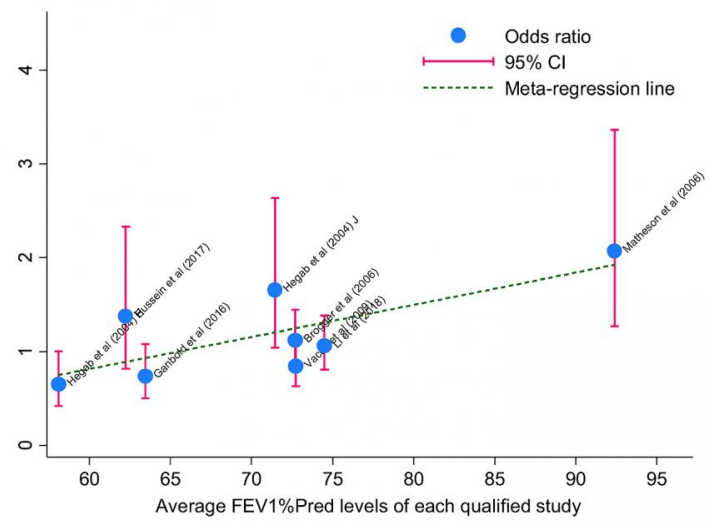

C. Average FEV1 levels by rs 1042714

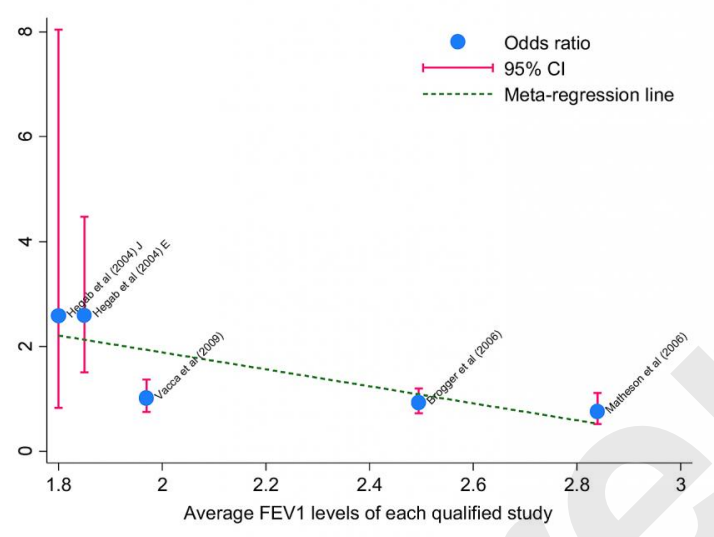

B. Average FVC\%Pred levels by rs 1042713

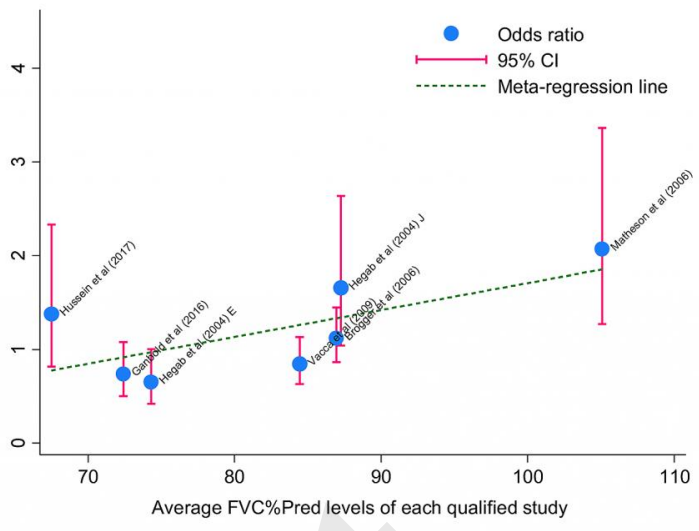

D. Average FEV1/FVC ratio levels by rs1042714

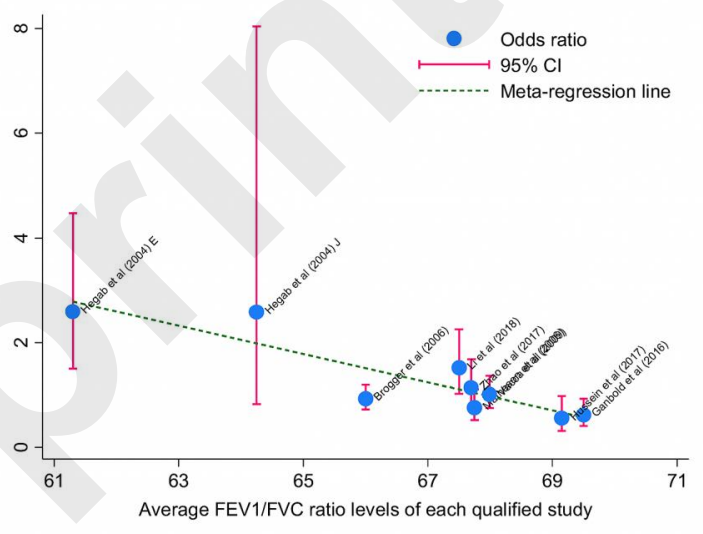

